\title{
Neonatal Bartter Syndrome
}

\section{F. BENNAOUI ${ }^{1,2}$, N . EL IDRISSI SLITINE ${ }^{1,2}$, F.M.R MAOULAININE ${ }^{1,2}$}

1. Neonatal Intensive Care Department, Mohammed VI University Hospital

2. Research Team for Childhood, Health and Development,. Marrakech School of Medicine, Cadi Ayyad University, Marrakech.

\section{Introduction}

Bartter syndrome is an inherited rare autosomal recessive tubulopathy characterized by hypochalemic hypochalemic metabolic alkalosis due to a sodium reabsorption disorder responsible for salt loss with hyperaldosteronism.

\section{Objective}

The aim of our work is to focus on rare desease with neonatal revelation through a clinical case with a littérature revue.

\section{Case report}

12-day's-old newborn; non-consanguineous marriage. The mother had a hydramnios. Hospitalized in Neonatal Intensive Care Unit, Mohammed VI University Hospital; MARRAKESH for somnolence and dehydration without other signs associated notably no vomiting and no diarrhea.

The clinical examination : Table $B$ dehydration without anomalies of sexual differentiation and no polyuria.

\section{The blood analysis :}

Hypokalaemia: $2.3 \mathrm{mmol} / \mathrm{I}$; Metabolic alkalosis:31 mmol/l Hypochloraemia :79

The urinary ionogram : without abnormality. Renal ultrasound : grade 1 nephrocalcinosis. The management : intravenous rehydration with potassium supplementation, indomethacin was not started due to the patient's low age.
Clinical-biological evolution: was good with a follow-up of 4 months.

\section{Discussion}

Bartter syndrome is a rare metabolic renal tubular disorder characterized by

hypokalemic, hypochloremic metabolic alkalosis, normal blood pressure hyperreninemia, and increased urinary loss of sodium, potassium, and chloride.

Its estimated prevalence is 1 per million. Depending On

The type, it may present in neonatal period, early childhood, or adolescent age.

Therapeutic efforts should be directed to correct dehydration and electrolytic imbalance. Apart from potassium supplementation, administration of non steroidal anti-inflammatory drugs is useful. Indomethacin at a dose of 1-5 $\mathrm{mg} / \mathrm{kg} /$ day is most frequently used and well tolerated.

The early diagnosis and proper treatment, barter syndrome has good prognosis but failure to identify it can lead renal failure.

\section{Conclusion:}

The early diagnosis of this syndrome allows the rapid introduction of a suitable and specific symptomatic treatment based on indomethacin from the first months of life; in order to optimize the growth of the body weight and avoid accidents of chronic dehydration. 